\title{
Placebo effects in chronic pain conditions. Can placebo components enhance the efficacy of active treatments?
}

Ina Skyt \& Lene Vase

Department of Psychology and Behavioural Sciences, School of Business and Social Sciences, Aarhus University

Danish Pain Research Center, Aarhus University Hospital

skyt@psy.au.dk; lenevase@psy.au.dk

Skyt, I. \& Vase, L. (2015). Placebo effects in chronic pain conditions. Can placebo components enhance the efficacy of active treatments?, Tidsskrift for Forskning $i$ Sygdom og Samfund, nr. 23, 63-88.

The conceptualization of the placebo phenomenon has changed. Previously placebo was seen as an inactive agent, but today placebo effects are viewed as related to patients' perception of a treatment. During the last decades, the mechanisms underlying placebo analgesia effects have been specified and it has been shown that patients' perception of a treatment is influenced by previous experiences, the patient-practitioner relationship as well as expectations and emotions. These factors are, in turn, associated with altered brain activation and release of endogenous opioids, thereby demonstrating that placebo analgesia has a psycho-neurobiological basis. The placebo effect has primarily been investigated in relation to healthy volunteers, but here we review literature on placebo mechanisms in relation to chronic pain states as this is important for an understanding of how placebo factors can be optimized in clinical practice. We outline some of the ethical discussions concerning the use of placebo in clinical practice and we illustrate how patients perception of a treatment contribute to the efficacy of active treatments, thereby showing how focus on patients per- 
ception of a treatment may help optimize the outcome of standard active pain treatments in ethically appropriate ways.

\section{Introduction}

Traditionally, placebos have been seen as inactive agents used as control conditions for active agents under study in randomized clinical trials (Andersen 1997). During the last decades, however, the conceptualization of the placebo phenomenon has evolved and today the placebo effect is associated with subjects' or patients' perception of receiving a treatment (Price, Finniss \& Benedetti 2008; Vase, Nørskov, Petersen \& Price 2011; Vase, Riley \& Price 2002). The psychosocial and neurobiological mechanisms underlying placebo analgesia effects in particular are being unraveled (Benedetti 2009; Bingel et al. 2006; Price, Finniss \& Benedetti 2008; Wager et al. 2004) and, importantly, it has been shown that placebo components do not only contribute to the efficacy of inactive placebo agents but also to the efficacy of active pharmacological agents (Benedetti 2009; Benedetti \& Amanzio 2011; Kam-Hansen et al. 2014; Kaptchuk et al. 2008; Klinger, Soost, Flor \& Worm 2007; Petersen et al. 2012; Price et al. 2007; Schenk, Sprenger, Geuter \& Büchel 2014; Vase, Robinson, Verne \& Price 2003, 2005). Hence, by optimizing the placebo components of active pain relieving treatments, it may be possible to enhance the overall treatment outcome. So far, placebo research has mostly involved healthy volunteers (Benedetti 2008; Price, Finniss \& Benedetti 2008). However, in order to fully understand how placebo effects can be optimized in clinical practice, it is pivotal also to understand the mechanisms underlying placebo effects in chronic pain patients as placebo effects in healthy volunteers exposed to experimental pain and chronic pain patients may differ (Hyland 2001; Klinger \& Flor 2013; Vase, Skyt, Petersen \& Price 2014). This review will outline current knowledge of placebo effects in chronic pain states and discuss how placebo components of treatments can be

optimized in clinical practice. Moreover, we will discuss ethical dilemmas related to the use of placebo effects in clinical practice and put forward ideas of how placebo components can be optimized in ethically appropriate ways. 


\section{Conceptualization of the placebo effect}

\section{Definitions}

The word 'placebo' is derived from Latin and means 'I want to please' (Andersen 1997). With the introduction of the randomized controlled trial (RCT), placebos became conceptualized as inert agents or sham treatments (e.g., sugar pill or saline injection) used as control conditions for active treatments under study in order to demonstrate the efficacy of new medications.

In order to understand the current conceptualization of the placebo phenomena it is important to differentiate between the placebo effect, the placebo response and the natural history of a disease (see Figure 1). Pain, for example, fluctuates over time and the natural history of a migraine attack is likely to follow the curve in $1 \mathrm{~A}$, where pain reaches a maximum and vanishes by itself without a treatment. In RCTs, inactive placebo treatments are typically given when the pain intensity is high and the subsequent reduction in pain may be termed the placebo response (Kirsch 2013; Vase \& Petersen 2013). However, it is important to be aware that since this placebo response is not controlled for the natural history of the pain, it is not possible to deduce whether the observed pain reduction is due to the treatment itself or to confounding factors like the natural history of the pain, regression to the mean or the like (see Figure 1B) (Benedetti 2009; Fields \& Price 1997). In order to verify that the observed pain reduction is due to the placebo intervention, it is essential to control for the natural history of the pain and to calculate the placebo effect (see Figure 1C). This can be done by including a placebo-treated group/ condition and a no-treated group/condition and estimating the placebo effect as the difference in pain levels between the two groups/conditions. Hence, the main difference between the placebo response and the placebo effect is that the latter is controlled for confounding factors thereby making it is possible to conclude that the observed pain relief is due to the administered placebo treatment (Benedetti 2009; Kirsch 2013; Vase \& Petersen 2013). 


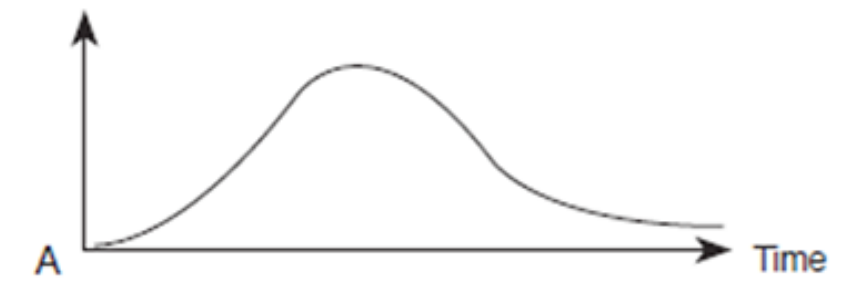

\section{A: Natural history of pain}

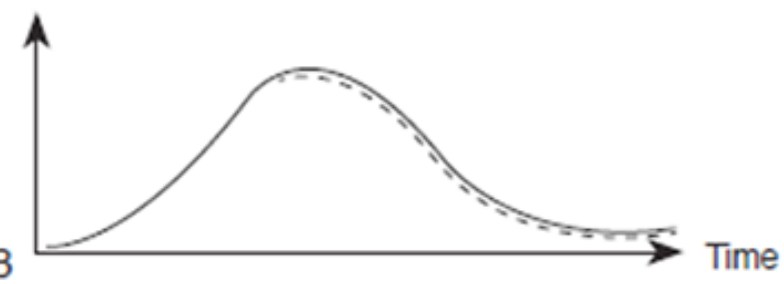

B: Improvement following administration of inert placebo agent

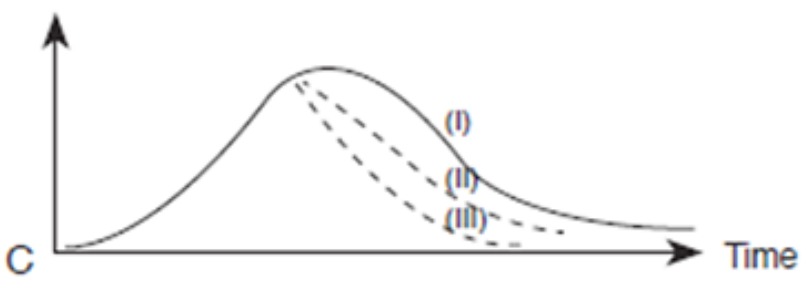

C: Reduction in pain after no treatment (I), placebo treatment (II) and active treatment (III)

Figure 1. The development of pain is illustrated under three different conditions. A: No treatment control condition showing the natural history of the pain. B: Treatment with an inert placebo agent showing that the pain reduction following administration of an inert treatment may be due to the natural history of pain rather than to the treatment. C: No treatment (I), placebo treatment (II), and active treatment (III) allowing for a calculation of the placebo analgesia effect as the difference between the no treatment and the placebo treatment group/condition.

It is widely accepted that placebo effects are related to psychosocial factors surrounding a treatment such as the verbal suggestions provided by practitioners and expectation about low pain levels (Benedetti 2009; Price, Finniss \& Benedetti 2008). Based on this knowledge, the placebo effect has been defined as the reduction in a symptom as a result of factors related to the subject's/patient's perception of the therapeutic intervention (Vase, Riley \& Price 2002). In addition, some authors have even suggested that the phrase 'placebo effect' should be replaced 
by terms such as 'meaning response' (Moerman 2013), 'context effect' (Di Blasi \& Kleijnen 2003) or 'expectation effect' (Kirsch 1999).

\section{Current designs to investigate placebo effects}

The change in the conceptualization of the placebo phenomena has led to advanced ways of investigating placebo effects. In traditional studies of placebo effects, inactive placebo treatments are administered and researchers are interested in the difference in pain levels between placebo-treated and no-treated control groups/ conditions (Benedetti 2008, 2009; Price, Finniss \& Benedetti 2008; Vase \& Petersen 2013).

As researchers became more interested in the psychosocial factors related to placebo effects, designs that allowed for manipulation of these factors evolved. One such design is the balanced placebo design, which is a 2 by 2 design, where administration of an inactive placebo treatment and an active treatment are balanced with correct and false information about the treatment (see Figure 2) (Kirsch \& Weixel 1988; Ross, Krugman, Lyerly \& Clyde 1962). By using this design, it is possible to evaluate drug effects (given active agent, told placebo), placebo effects (given placebo, told active agent), and total treatment effects including active drugs and placebo components (given active agent, told active agent). Also, a baseline condition is included (given placebo, told placebo) against which active and placebo treatments can be compared.

\section{Get}

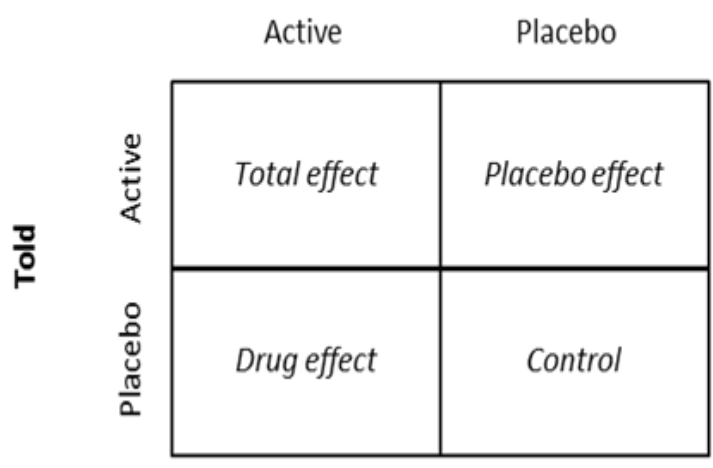


Figure 2. The balanced placebo design. Administration of inactive placebo treatments and active drug treatments are balanced with correct and false information about the treatment. The design allow for calculation of the total effect of the active drug plus the placebo effect (get active, told active), the placebo effect (get placebo, told active), and the drug effect (get active, told placebo). The design also includes a control condition (get placebo, told placebo) against which the effect of the drug, the placebo and a combination of drug and placebo can be compared.

The balanced placebo design is interesting because it reveals how psychosocial factors, such as the verbal information given by the practitioner, can influence the efficacy of both active and inactive treatments. More recently, the balanced placebo design has been utilized to specify the relative contribution of the drug effect and the placebo effect to an overall treatment outcome, thereby furthering the understanding of possible interactions between placebo and drug effects (Atlas et al. 2012; Lund et al. 2014; Schenk, Sprenger, Geuter \& Büchel 2014).

The open/hidden design is another placebo design, allowing for examination of psychosocial placebo components of a treatment without administration of inactive placebo treatments (see Figure 3) (Amanzio, Pollo, Maggi \& Benedetti 2001; Benedetti, Carlino \& Pollo 2011; Levine \& Gordon 1984; Levine, Gordon \& Fields 1978). This design focuses on patients' perception of a treatment and only active agents are given. In one condition, a practitioner administers an active treatment in full view of the patients and gives verbal information about pain relief (open condition) (see Figure 3A). In another condition, the same active agent is given without the patients' knowledge, e.g. via a computer-controlled infusion pump (hidden condition) (see Figure 3B). Only in the open condition, patients perceive the treatment and thereby form expectations about pain relief, and the placebo effect is calculated as the difference in pain levels between the open and the hidden administration, controlled for natural history of the pain. Hence, the open/hidden design allow for a calculation of the pharmacological component of a treatment (hidden condition) and the psychosocial placebo component of the treatment (open minus hidden condition), thereby making it possible to investigate how each of these factors contribute to the overall treatment effect. This design relates to the more modern view of placebo effects. Given that no inactive treatments are given and that patients' perception is manipulated instead, this design represents an ethically acceptable investigation of the placebo effect and thereby illustrates how psychosocial placebo components can be applied in clinical practice. 

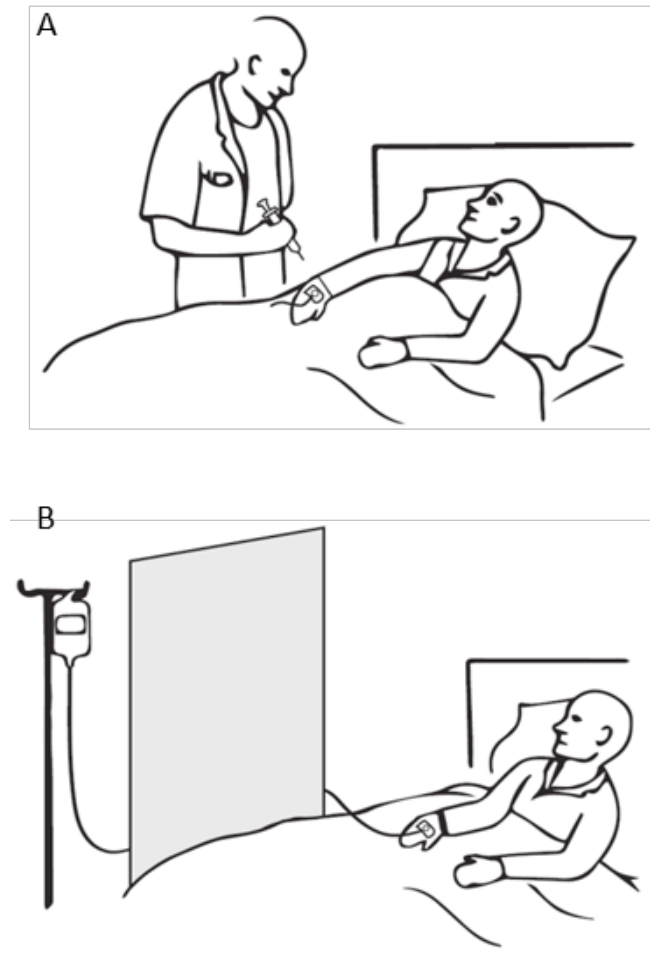

Figure 3. The open/hidden placebo design. The same active treatment is given in an open and a hidden manner. In the open condition, the treatment is given by a practitioner in full view of the patient $(A)$, while in the hidden condition, the active treatment is given without the patient's knowledge, e.g. via a computer-controlled infusion pump (B). The placebo effect is calculated as the difference in pain levels between the open and the hidden condition, controlled for natural history of the pain

\section{Treatment history}

Placebo analgesia effects appear to be critically influenced by prior treatment experiences in either negative or positive ways. This has been well documented in healthy volunteers and it also seems to apply chronic pain conditions (Colloca et al. 2010; Kessner et al. 2013b; Laska \& Sunshine 1973; Voudouris, Peck \& Coleman 1989, 1990). Kessner \& colleagues (2013b) conducted a study of healthy volunteers where the influence of previous treatments was directly investigated. In this 
study, 39 healthy participants were exposed to painful heat stimuli at the left forearm. The pain corresponded to an individual pain level of 80 on a 0-100 visual analogue scale. The study took place over three days and on each day an inert analgesic treatment was administered; nevertheless, participants were told that an active analgesic was given. On the first two test days, when the (inert) analgesic treatment was administered, the heat pain intensity was surreptitiously decreased from 80 to 20 in half of the participants to give the participants an experience of pain relief (positive treatment history group), whereas it remained stable in the other half of the participants (negative treatment history group). Hence, participants in the positive group were conditioned to experience a pain relieving effect of the treatment, whereas the negative group was not. On the third test day, a new inert analgesic was administered and the heat pain intensity was surreptitiously decreased from 80 to 50 in all participants. Interestingly, the effect of the inert analgesic was significantly higher in the group who had previously experienced a pain relieving effect than in the group who had not. This study indicates that negative and positive treatment experiences can influence later treatments.

The importance of prior treatment experiences have not been directly investigated in chronic pain patients. However, a salient study by Laska \& Sunshine (1973) indicates that treatment history may indeed influence clinical pain treatment. In this study, a mixed group of pain patients received two analgesic treatments, the second always being a placebo treatment. The first treatment consisted of either the active analgesics propoxyphene HCL or propoxyphene napsylate administered in three graded doses or a placebo treatment. Hence, the study included seven groups of patients with twelve to twenty patients in each group. Results showed a convincing dose-response relationship between the dose of the first analgesic treatment and the subsequent placebo treatment so that the placebo given as a second treatment acted as an effective analgesic when it followed an active analgesic, whereas the placebo following another placebo treatment only had a small analgesic effect. Although this clinical trial did not control for patients' natural pain history, it supports the involvement of learning or conditioning processes in placebo effects in chronic pain patients.

Taken together, these data suggest that treatment of chronic pain is affected by prior treatment history. This may have considerable implications for clinical practice because chronic pain patients often have a long history of treatment failures (Kessner et al. 2013b; Klinger \& Flor 2013). Clinicians may actively try to reduce the influence of patients' negative treatment experiences by creating new and po- 
sitive associations between treatment effects and pain medication (Klinger \& Flor 2013).

\section{The patient-practitioner relationship}

The specific relationship between a patient and a practitioner may also affect placebo effects in chronic pain states. In a study by Kaptchuk and colleagues (2008), 262 patients suffering from Irritable Bowel Syndrome (IBS) were divided into three different treatment groups. The first group received no treatment (control). The second group received three weeks of a so-called 'limited placebo acupuncture', whereas the third group received so-called 'augmented placebo acupuncture'. The placebo acupuncture was the same in group two and three, and only factors related to the psychosocial context differed. In the second group (limited placebo acupuncture), the patient-practitioner relationship was established in less than five minutes at the initial visit. In this setup, the doctor introduced himself and then informed the patient that the study was scientific and the doctor was instructed not to converse with the patients. Contrary to this, in the third group (augmented placebo acupuncture) the patient-practitioner relationship was established during a 45-minute initial visit and the practitioner acted warmly, friendly, and emphatically and communicated positive expectations about the treatment. The aim of the latter approach was to obtain a so-called optimal patient-practitioner relationship. The treatment outcome was measured using four different scales (global improvement scale, adequate relief of symptoms, symptom severity score, and quality of life) and for all outcome measures the same symptom progression appeared. The smallest symptom reduction followed the control group (no treatment). The limited placebo acupuncture was more effective than the control; however, the effect of the augmented placebo acupuncture was significantly larger than the limited placebo acupuncture across all outcome measures. These results indicate that the type of patient-practitioner relationship influences clinical outcome.

To better understand the association between placebo effects and the patientpractitioner relationship, the research group further elaborated the influence of specific patients characteristics (i.e., personality traits and demographics), practitioner effects (i.e., a combined score based on the four IBS scales cf. above), and the nature of the interpersonal interaction (i.e., recorded on videotapes and rated via the Psychotherapy Process Q-set (PQS) by independent clinical judges) (Kelley et al. 2009). Prior to the study, a prototype of an ideal healthcare encounter was con- 
structed against which the patient-practitioner interaction in the study could be compared (for further information see Kelley et al. 2009). The results showed that patient characteristics like extraversion, agreeableness, openness, and female gender were associated with the placebo effect. Also, there were significant differences in outcomes between different practitioners, indicating that practitioners can have relatively large differential effects on the placebo effect, even when treatment is highly standardized. Importantly, the study revealed that the patient-practitioner relationship in the augmented placebo group was successful and highly correlated with the prototype of the ideal healthcare encounter. In contrast, the patient-practitioner relationship was only moderately correlated with the ideal healthcare prototype in the limited placebo group, thereby indicating that the sharp difference in the nature of the patient-practitioner interaction between the limited and augmented placebo groups is likely to be responsible for the differences in treatment outcome.

Another interesting study has tested whether the placebo effect can be pharmacologically boosted by the neuropeptide oxytocin in healthy volunteers (Kessner et al. 2013a). Oxytocin is involved in processes such as empathy and trust, which are key elements of the patient-practitioner relationship. The study compared the placebo effect across participants receiving oxytocin and participants receiving inert saline (control). An inert analgesic treatment was used to induce placebo effects. Data revealed that the placebo response was significantly higher in the oxytocin group than in the control group. Based on the effect on empathy and trust, it was proposed that the administration of oxytocin increased participants' believability of the instructions of the doctor and thereby enhanced the placebo effect. This study supports the notion that factors related to the patient-practitioner relationship such as empathy, trust and warmth are important components of placebo responsiveness.

Based on the hypothesis that reciprocal interactions between patient and doctor may be involved in placebo effects (in addition to the patient perspective alone), one study has examined the activation of the doctor's brain while treating pain patients (Jensen et al. 2014). Results revealed that brain regions associated with expectancy for pain relief such as the right ventrolateral and dorsolateral prefrontal cortices was activated in doctors while treating patients. Moreover, the doctor's ability to take the patient's perspective correlated with activity in the rostral anterior cingulate cortex, a region that has been associated with reward and subjective value. This study suggests that placebo analgesia effects may be dependent on the 
perspective of both the patient and the doctor and, consequently, emphasizes the importance of the reciprocal relationship between the doctor and the patient.

Overall, data suggest that an empathic, warm and trusting patient-practitioner relationship is an important factor in establishing placebo effects and positive therapeutic outcome leading to pain relief. Thus, based on these findings it is recommended that practitioners focus on the patient-practitioner relationship in clinical practice in order to improve treatment outcomes.

\section{Verbal suggestions}

The verbal suggestions that doctors provide to patients are central to placebo effects. This has directly been shown in two studies of Irritable Bowel Syndrome (IBS) patients performed by Vase and colleagues (2003) and Verne and colleagues (2003). In both studies, patients went through similar placebo treatments, however, the studies varied according to the verbal suggestions given. The study by Vase and colleagues was conducted as a placebo mechanism study and patients were told that 'the agent you have just been given is known to significantly reduce pain in some patients'. Contrary to this, the study by Verne and colleagues was designed as a clinical trial where patients via the informed consent were told 'you may receive an active pain reducing medication or an inert placebo agent'. Results from the two studies showed that the placebo mechanism study with enhanced verbal suggestions induced markedly larger placebo analgesia effects than the clinically designed study. In fact, the magnitude of the placebo analgesia was so high that there was no significant difference between the placebo and the active treatment, indicating that by adding a verbal suggestion for pain relief it is possible to increase the magnitude of placebo analgesia to a level that matches that of an active agent (Vase, Robinson, Verne \& Price 2003).

Recently, a landmark study by Kam-Hansen and colleagues (2014) has further elaborated the verbal suggestions given for pain relief in relation to both a placebo treatment and an active treatment. This study used an extended, balanced placebo design, in which active (Maxalt, 10-mg rizatriptan) and inactive placebo pills were given with three types of information (negative $=$ told placebo, uncertain $=$ told placebo or active agent, positive = told active). Hence, 66 patients with episodic migraine were tested in seven different sessions. The primary outcome measure was the change in headache between the baseline pain score reported 30 minutes after the onset of headache and the pain score recorded two hours later. Several 
interesting results can be derived from this study. First, the outcome of both inert placebo and active drug treatments improved with stronger verbal suggestions about treatment effects, i.e., effects of both inert placebo and active medication were highest when treatment was labeled as active medication or had uncertain labeling, and lowest when treatments were labeled as placebo. Second, the effect of the mislabeled active drug (given active agent, told placebo) was similar to the mislabeled inert placebo (given placebo, told active agent). Third, relative to no treatment, the placebo, under each information condition, accounted for more than 50 percent of the drug effect. These data emphasize that the efficacy of both active drugs and inert placebos may indeed be modulated by verbal information about treatment effects.

The critical influence of verbal suggestions has been supported by studies using the open/hidden design that resembles clinical practice to a great extent (Petersen et al. 2012, 2014). In two similar studies, neuropathic pain patients received open and hidden administrations of the active pain relieving agent lidocaine. In the open condition, lidocaine was administered in full view of the patient and followed by the verbal suggestion that 'the agent you have just been given is known to powerfully reduce pain in some patients'. In the hidden condition, lidocaine was administered without the patient's knowledge and without any verbal suggestions about pain relief. Importantly, the patients received the same pharmacological agent in the open and hidden conditions and only the psychosocial placebo components differed. Results from the studies showed that significant placebo effects can be obtained in spontaneous neuropathic pain as well as in different types of evoked pain such as area of hyperalgesia, pinprick hyperalgesia, and wind-up like pain. Overall, these studies support the notion that adding a verbal suggestion for pain relief may increase the effect of an active pharmacological pain relieving treatment.

In general, studies giving positive and certain verbal suggestions for pain relief find larger magnitudes of placebo effects compared to studies with uncertain or negative verbal suggestions, proposing that placebo effects can profitably be optimized in clinical practice by shaping verbal suggestions in specific ways (Kaptchuk et al. 2008; Price et al. 2007). Hence, practitioners should be careful when informing patients about treatment effects and try to point out positive and realistic expectations, yet without deceiving or misleading patients. 


\section{Expectations and emotional feelings}

Previous treatment experiences, the patient-practitioner relationship and the verbal suggestions given for pain relief are likely to influence patients' expectations about pain relief. Several studies have shown that expectations about low pain levels contribute to placebo effects in both healthy volunteers and in chronic pain patients (Bingel et al. 2011; Kirsch 1999; Price et al. 1999; Vase, Robinson, Verne \& Price 2003; 2005). Measures of expected pain levels are typically assessed by asking patients 'what do you expect your pain level to be?' right after a treatment has been administered and before it has taken effect. Patients then indicate their expected pain level on a visual analogue scale ranging from 'no pain' to the 'worst pain imaginable' (Petersen et al. 2012; Price et al. 1999; Vase, Robinson, Verne \& Price 2003). In a study including patients suffering from IBS, expected pain levels along with desire for pain relief accounted for up to 81 percent of the variance in pain levels following both inactive placebo treatments and active lidocaine administrations (Vase, Robinson, Verne \& Price 2003). A second study supported the result and showed that expected pain levels along with desire for pain relief and anxiety levels accounted for up to 73 percent of the variance in pain levels following both placebo and active treatments of IBS patients (Vase, Robinson, Verne \& Price 2005). In both studies, ratings of expected pain levels were the only unique predictor for the variance in pain levels. Therefore, optimizing patients' expectations about treatment effects via for example verbal suggestions may lead to improved treatment outcomes in medical practice.

Research including both healthy volunteers and chronic pain patients indicate that positive and negative emotions are also involved in placebo effects (Flaten et al. 2006; Flaten, Aslaksen, Lyby \& Bjørkedal 2011; Petersen et al. 2012, 2014; Vase, Robinson, Verne \& Price 2005). A number of studies have, for example, shown that high levels of negative emotions like stress and fear reduce or abolish placebo effects (Lyby, Aslaksen \& Flaten 2010; Lyby, Forsberg, Åsli \& Flaten 2012). Lyby and colleagues (2012) has examined the effect of fear on placebo analgesia in healthy volunteers exposed to experimental pain. In a within-subject design, participants were given placebo pills followed by the information that they contained a powerful painkiller (placebo condition). In order to induce fear, participants were shortly after told that they would receive electric shock (placebo plus fear condition). The placebo effects in the placebo plus fear condition was compared to the placebo effect in the placebo condition alone, and to a natural history condition without any placebo or fear manipulations. The study revealed that induced fear 
abolished the placebo effect. In addition, the abolished placebo effect was most pronounced in participants who reported the highest level of fear.

Two subsequent studies have examined the involvement of negative as well as positive emotions in placebo effects in neuropathic pain patients (Petersen et al. 2012 , 2014). Both studies used open and hidden administrations of lidocaine to induce placebo effects. In the first study, the Positive Affect Negative Affect Schedule (PANAS), listing twenty predefined emotions divided into a positive and a negative affect scale, was used to assess the contribution of emotions in placebo effects (Petersen et al. 2012). Results from the study showed that a low score on the negative affect scale was associated with placebo analgesia, while the positive affect scale was not associated with placebo analgesia. The second study assessed emotions during the placebo intervention by directly asking patients about their experiences immediately after the placebo treatment was administered and before it had taken effect (Petersen et al. 2014). Patients were asked to quantitatively rate their expected pain levels on a mechanical visual analogue scale and to qualitatively describe their emotions in a few words. Following the open condition, patients reported higher intensities of positive than negative emotions. These findings suggest that high levels of positive emotions and low levels of negative emotions are related to the pain experience during placebo interventions. This relationship is also consistent with research on clinical pain, which shows that negative emotions increase painful sensations, while positive emotions reduce painful sensations (Keefe et al. 2001; Rhudy et al. 2008). The study further indicated that patients' expectations are closely related to their emotions as illustrated by a patient saying 'I am hoping that the cream will bring relief'.

Overall, when treating chronic pain patients it may be important to remember that expectations co-exist with emotions. Consequently, practitioners who try to optimize treatment expectations may also benefit from paying attention to patients' emotions with the aim of preventing negative emotions and promoting positive emotions (Flaten, Aslaksen \& Lyby 2013).

\section{Neurobiological basis for placebo analgesia in chronic pain disorders}

Whether placebo effects represent neurobiological phenomena rather than simple response bias has been extensively debated (Benedetti \& Frisaldi 2013; Eippert \& 
Büchel 2013; Hróbjartsson \& Gøtzsche 2001, 2004; Pecina \& Zubieta 2013; Vase, Riley \& Price 2002; Vase, Petersen, Riley \& Price 2009). Brain imaging performed in healthy volunteers has shown that placebo analgesia is associated with increased activity in cortical areas as the dorsolateral prefrontal cortex (DLPFC) and orbitofrontal cortex (OFC), which may be associated with expectations of pain relief (Wager et al. 2004), as well as in the rostral anterior cingulate cortex (rACC) and the periaqueductal gray (PAG) (Amanzio et al. 2013; Atlas \& Wager 2012; Bingel et al. 2006; Kong et al. 2006; Petrovic, Kalso, Petersson \& Ingvar 2002). In addition, placebo analgesia is related to decreased neural activity in areas of the so-called pain matrix like the thalamus, the insula, and the anterior cingulate cortex (Wager et al. 2004). Hence, placebo analgesia involves top-down modulation of pain and it has even been shown to inhibit pain-related activity at levels of the spinal cord (Eippert, Finsterbusch, Bingel \& Büchel 2009). One functional neuroimaging study has demonstrated that placebo analgesia in IBS patients is also associated with reductions in neural activity in areas of the pain matrix (thalamus, insula, somatosensory cortices, and anterior cingulate cortex) (Price et al. 2007). Several pharmacological studies have shown that the opioid antagonist, naloxone, can block placebo analgesia in healthy volunteers, suggesting that the endogenous opioid system is involved in these placebo effects (Amanzio \& Benedetti 1999; Benedetti 1996; Gracely, Dubner, Wolskee \& Deeter 1983; Levine, Gordon \& Fields 1978; Zubieta et al. 2005). Contrary to this, naloxone has not been able to block placebo analgesia in chronic pain states (Kupers et al. 2007; Vase, Robinson, Verne \& Price 2005). Recently, it was shown that non-opioid mediated placebo analgesia effects in healthy volunteers can be blocked by the cannabinoid antagonist rimonabant (Benedetti, Amanzio, Rosato \& Blanchard 2011; Benedetti et al. 2013). In addition, studies employing functional molecular imaging have observed increased dopamine release in areas such as the nucleus accumbens, typically related to processes of reward and motivation, during placebo administrations in healthy volunteers, which is likely to be related to the anticipation of a treatment effect (Scott et al. 2007, 2008). So far the endocannabinoid and the dopaminergic systems have not been examined in relation to chronic pain states.

\section{Ethical considerations}

Although deceptive administration of inactive placebo pills may lead to pain relief as shown above, this is considered unethical and is not recommended in cli- 
nical practice (Price 2005). If patients find out that they have been deceived, this is likely to ruin the patient-practitioner relationship and it may undermine the efficacy of future treatments. However, surveys show that a large proportion of practitioners do prescribe placebos understood as inactive treatments (pure placebos) or treatments that do not have any known effect on the condition for which it is given (impure placebos) (Fässler, Meissner, Schneider \& Linde 2010; Hróbjartsson \& Norup 2003; Miller \& Colloca 2009; Tilburt et al. 2008). For instance, a questionnaire study of Danish practitioners showed that during the previous year 86 percent of general practitioners, 54 percent of hospital-based physicians, and 41 percent of private specialists had used impure placebo interventions where an active medication was given although the pharmacological effect on the disease is known to be negligible (Hróbjartsson \& Norup 2003). Similar data has been found in the United States, Europe and Israel (Kermen, Hickner, Brody \& Hasham 2010; Linde et al. 2014; Nitzan \& Lichtenberg 2004; Tilburt et al. 2008). Notably, clinicians in the study of Danish practitioners most often explained the impure placebo interventions in terms of 'following the wish of the patient and avoid conflict', which questions whether the administration of placebo agents take place in a good patient-practitioner relationship and thereby whether it will in fact lead to a placebo effect. Recently, patients have been asked directly about their attitude toward inactive placebo administration and it was actually found that many patients are open to the idea of inactive placebo treatments (Hull et al. 2013). A study including patients with a chronic health problem found that most patients (up to 84 percent) judged that it was acceptable for doctors to recommend placebo treatment if they for instance thought that the treatment would benefit and not harm the patient (ibid.). Only 21.9 percent judged that it was never acceptable for doctors to use placebo treatments. Nevertheless, patients valued honesty and trust, which was illustrated by patients saying that doctors should be honest about an intervention being a placebo intervention when patients ask specific questions about the treatment.

It has been a general assumption that inactive placebo agents are only effective if they are given deceptively. Recently, however, this assumption has been challenged. In a couple of studies, patients have been given so-called open-label placebo, i.e., patients are specifically informed that they receive inactive placebo treatments and, surprisingly, these studies yield large placebo effects. In a landmark study by Kaptchuk and colleagues (2010), 80 IBS patients were divided into two groups, one group received inert placebo pills in an open manner, and the other group received no treatment (control group). The placebo group was given pla- 
cebo pills in a typical medicine bottle labelled 'placebo pills' - 'take two pills twice daily' and told that 'placebo pills, something like sugar pills, have been shown in rigorous clinical testing to produce significant mind-body self-healing processes'. Patients in the control group were not given any medication but were reminded of the importance of a control arm. Information in both the control and the placebo group was given in the context of a warm, supportive patient-practitioner relationship. Results showed that the placebo-treated patients improved significantly more than the patients in the control group. This finding is supported by a study by Kam-Hansen and colleagues (2014), in which open-label administrations of inert placebos led to greater symptom reduction in migraine patients than in a no-treated control group. Overall, these studies indicate that openly administered inactive placebo treatments without deception can contribute to treatment outcomes, thereby furthering that the bare presence of psychosocial factors like a supportive patient-practitioner relationship and a specific treatment ritual can lead to clinically meaningful symptom improvements probably because patients expect an effect. Yet, although it is possible to administer inactive agents in ethical acceptable ways, it is generally recommended to administer active agents and at the same time pay attention to patients' perception of the treatment.

As listed in the introduction, the placebo effect is seen as related to patients' perception (Vase, Riley \& Price 2002). Hence, the placebo components of a treatment can be enhanced by focusing on patients' perception of the treatment. This is elegantly shown in the described studies using the open/hidden placebo design, where patients who are told that an active treatment is given experience significantly more pain relief than patients who are not told that an active treatment is administered (Petersen et al. 2012, 2014). Thus, by actively focusing on patients' perception of the treatment, it may be possible to enhance the placebo component of the treatment and thereby the overall treatment outcome. At present, this appears to be the best way to optimize placebo factors in clinical practice. Recent clinical trials have shown that pain patients who are treated by doctors scoring high on factors such as empathy and communication skills, experience better symptom improvement than patients treated by doctors not scoring high on these factors (Hojat et al. 2011; Kelley et al. 2014). Hence, these studies provide specific information on how patients' perception of a treatment may be optimized and thereby contribute to the efficacy of active treatments. 


\section{Awareness of placebo components is critical in clinical practice}

The finding that patients' perception of a treatment contributes to the efficacy of both active and inactive treatments has led to new ways of integrating knowledge of placebo factors in clinical practice. The discussion is no longer whether inactive agents should be administered in ethically questionable ways, but rather how active agents can be administered in a context that favors the patient's perception of the treatment so the overall treatment efficacy can be enhanced (Benedetti 2009; Benedetti \& Amanzio 2011; Kirsch 2013; Klinger \& Flor 2013; Lichtenberg, Heresco-Levy \& Nitzan 2004). In this article, we have primarily shown how previous experiences, the patient-practitioner relationship as well as expectations and emotions may contribute to an enhanced treatment outcome.

Studies investigating how patients' negative perception and expectations towards treatment contribute to treatment outcomes are also emerging (Amanzio, Corazzini, Vase \& Benedetti 2009; Bingel et al. 2011; Rief, Avorn \& Barsky 2006). In a study by Bingel and colleagues (2011), the analgesic treatment remifentanil was administered under three information conditions (with no expectations of an analgesic, with expectancy of a positive analgesic, and with negative expectancy of exacerbation of the pain). Results revealed that the analgesic effect was enhanced (doubled) in the positive information condition. Importantly, however, the negative information completely abolished the effect of the analgesic treatment, thereby showing that negative expectations may block the efficacy of a welldocumented analgesic treatment. In line with this, a systematic review showed a high incidence of adverse events in placebo treated groups of anti-migraine clinical trials (Amanzio, Corazzini, Vase \& Benedetti 2009). Noteworthy, the adverse events experienced in different placebo arms corresponded to the adverse events produced by the actual drug against which the placebo was compared. Hence, adverse events may at least partially be a result of the information given in informed consent procedures about such events. Taken together, these findings show that patients' negative perception of a treatment may also lead to negative effects. Hence, it seems important for healthcare providers to try to shape for example expectations in a positive way. Unfortunately, in clinical practice, optimizing patients' expectations is often complicated as verbal suggestions and information sheets are primarily focused on negative information and fail to discuss positive treatment outcome in an equally clear manner (Klinger \& Flor 2013). In addition, observations in the United States show that 50 percent of all patients leave office 
visits without an adequate understanding of what the physician has told them (Bodenheimer 2008). Hence, negative or uncertain information may reduce or block the placebo component of a treatment and thereby contribute to poor treatment outcome.

Most studies have only investigated placebo effects in short-term studies and it has been assumed that the placebo effect is brief. Yet, recent studies indicate that the placebo effect may be long lasting and this is especially important for chronic pain patients. For example, in a study by Vase and colleagues (2005) temporal changes in the placebo effect and in psychological variables were examined. Results showed that the magnitude of the placebo effect increased during the 40 min of investigation and this change was partly explained by a decrease in psychological factors such as expectations, desire and emotions. In addition, placebo-controlled clinical trials of acupuncture in different painful conditions have shown that both active and placebo acupuncture can lead to marked symptom improvement lasting up to 6 months even in the placebo-treated patients, thereby suggesting that placebo effects maintain over long periods (Brinkhaus et al. 2006; Linde et al. 2005, 2007; Melchart et al. 2005; Witt et al. 2005). Thus, there is reason to believe that placebo effects can last for longer periods and factors like emotions, motivation, expectancy and previous treatment history appear to be central in the maintenance of these effects (Hyland 2011; Hyland, Geraghty, Joy \& Turner 2006; Hyland \& Whalley 2008; Hyland, Whalley \& Geraghty 2007; Klinger \& Flor 2013; Klinger, Soost, Flor \& Worm 2007; Petersen et al. 2014; Vase, Robinson, Verne \& Price 2005). Still, more research is needed to understand the long-term development of placebo effects and the mechanisms involved.

Overall the literature reviewed in this article suggests that psychosocial placebo components can interact with neurobiological factors and thereby contribute to the efficacy of standard pain treatments. Therefore, it may be very helpful for practitioners to be aware of how placebo components may either enhance or reduce the outcome of active treatment effects in chronic pain patients. By establishing a warm and empathic patient-practitioner relationship and by directly asking patients about expectations and emotions in an attempt to optimize them in a realistic manner, practitioners may have the opportunity to influence and optimize treatment outcome. 


\section{Acknowledgement}

Thanks to graphic designer Line Larsson for the use of Figure 1.

\section{References}

Amanzio, M., \& Benedetti, F. (1999). Neuropharmacological dissection of placebo analgesia: Expectation-activated opioid systems versus conditioning-activated specific subsystems. The Journal of Neuroscience: The Official Journal of the Society for Neuroscience, 19(1), 484-494.

Amanzio, M., Benedetti, F., Porro, C. A., Palermo, S., \& Cauda, F. (2013). Activation likelihood estimation meta-analysis of brain correlates of placebo analgesia in human experimental pain. Human Brain Mapping, 34(3), 738-752.

Amanzio, M., Corazzini, L. L., Vase, L., \& Benedetti, F. (2009). A systematic review of adverse events in placebo groups of anti-migraine clinical trials. Pain, 146(3), 261-269.

Amanzio, M., Pollo, A., Maggi, G., \& Benedetti, F. (2001). Response variability to analgesics: A role for non-specific activation of endogenous opioids. Pain, 90(3), 205-215.

Andersen, L. O. (1997). Placebo - historisk og kulturelt. In L. O. Andersen, M. H. Claësson, A. Hróbjartsson \& A. N. Sørensen (Eds.), Placebo. historie, biologi og effekt (pp. 69-118). Lyngby, Danmark: Akademisk Forlag.

Atlas, L. Y., \& Wager, T. D. (2012). How expectations shape pain. Neuroscience Letters, 520(2), 140-148.

Atlas, L. Y., Whittington, R. A., Lindquist, M. A., Wielgosz, J., Sonty, N., \& Wager, T. D. (2012). Dissociable influences of opiates and expectations on pain. The Journal of Neuroscience : The Official Journal of the Society for Neuroscience, 32(23), 8053-8064.

Benedetti, F. (1996). The opposite effects of the opiate antagonist naloxone and the cholecystokinin antagonist proglumide on placebo analgesia. Pain, 64(3), 535-543.

Benedetti, F. (2008). Mechanisms of placebo and placebo-related effects across diseases and treatments. Annual Review of Pharmacology and Toxicology, 48, 33-60.

Benedetti, F. (2009). Placebo effects: Understanding the mechanisms in health and disease. Oxford; New York: Oxford University Press.

Benedetti, F., \& Amanzio, M. (2011). The placebo response: How words and rituals change the patient's brain. Patient Education and Counseling, 84(3), 413-419.

Benedetti, F., Amanzio, M., Rosato, R., \& Blanchard, C. (2011). Nonopioid placebo analgesia is mediated by CB1 cannabinoid receptors. Nature Medicine, 17(10), 1228-1230.

Benedetti, F., Carlino, E., \& Pollo, A. (2011). Hidden administration of drugs. Clinical Pharmacology and Therapeutics, 90(5), 651-661.

Benedetti, F., \& Frisalde, E. (2013). Neurochemistry of placebo analgesia: opioids, cannabinoids and cholecystokinin. In L. Colloca, M. A. Flaten \& K. Meissner (Eds.), Placebo and pain - from bench to bedside (pp. 9-13). Amsterdam; Boston: Academic Press.

Benedetti, F., Thoen, W., Blanchard, C., Vighetti, S., \& Arduino, C. (2013). Pain as a reward: Changing the meaning of pain from negative to positive co-activates opioid and cannabinoid systems. Pain, 154(3), 361-367. 
Bingel, U., Lorenz, J., Schoell, E., Weiller, C., \& Büchel, C. (2006). Mechanisms of placebo analgesia: RACC recruitment of a subcortical antinociceptive network. Pain, 120(1-2), 8-15.

Bingel, U., Wanigasekera, V., Wiech, K., Ni Mhuircheartaigh, R., Lee, M. C., Ploner, M., \& Tracey, I. (2011). The effect of treatment expectation on drug efficacy: Imaging the analgesic benefit of the opioid remifentanil. Science Translational Medicine, 3(70), 70ra14.

Bodenheimer, T. (2008). The future of primary care: Transforming practice. The New England Journal of Medicine, 359(20), 2086-2089.

Brinkhaus, B., Witt, C. M., Jena, S., Linde, K., Streng, A., Wagenpfeil, S., Irnich, D., Walther, H. U., Melchart, D., \& Willich, S. N. (2006). Acupuncture in patients with chronic low back pain: A randomized controlled trial. Archives of Internal Medicine, 166(4), 450-457.

Colloca, L., Petrovic, P., Wager, T. D., Ingvar, M., \& Benedetti, F. (2010). How the number of learning trials affects placebo and nocebo responses. Pain, 151(2), 430-439.

Di Blasi, Z., \& Kleijnen, J. (2003). Context effects. Powerful therapies or methodological bias? Evaluation $\mathcal{E}$ the Health Professions, 26(2), 166-179.

Eippert, F., Büchel, C., (2013). Spinal and supraspinal mechanisms of placebo analgesia. In L. Colloca, M. A. Flaten \& K. Meissner (Eds.), Placebo and pain - from bench to bedside (pp. 53-65). Amsterdam; Boston: Academic Press.

Eippert, F., Finsterbusch, J., Bingel, U., \& Büchel, C. (2009). Direct evidence for spinal cord involvement in placebo analgesia. Science (New York, N.Y.), 326(5951), 404.

Fässler, M., Meissner, K., Schneider, A., \& Linde, K. (2010). Frequency and circumstances of placebo use in clinical practice--a systematic review of empirical studies. BMC Medicine, 23(8), 15-7015-8-15.

Fields, H. L., \& Price, D. D. (1997). Toward a neurobiology of placebo analgesia. In A. Harrington (Ed.), The placebo effect: An interdisciplinary exploration (pp. 93-116). Cambridge, Mass.: Harvard University Press.

Flaten, M. A., Aslaksen, P. M., Finset, A., Simonsen, T., \& Johansen, O. (2006). Cognitive and emotional factors in placebo analgesia. Journal of Psychosomatic Research, 61(1), 81-89.

Flaten, M. A., Aslaksen, P. M., Lyby, P. S., \& Bjørkedal, E. (2011). The relation of emotions to placebo responses. Philosophical Transactions of the Royal Society of London.Series B, Biological Sciences, 366(1572), 1818-1827.

Flaten, M., Aslaksen, P., \& Lyby, P. (2013). Positive and negative emotions and placebo analgesia. In L. Colloca, M. Flaten \& K. Meissner (Eds.), Placebo and pain - From Bench to bedside (pp. 73-81). Amsterdam; Boston: Academic Press.

Gracely, R. H., Dubner, R., Wolskee, P. J., \& Deeter, W. R. (1983). Placebo and naloxone can alter post-surgical pain by separate mechanisms. Nature, 306(5940), 264-265.

Hojat, M., Louis, D. Z., Markham, F. W., Wender, R., Rabinowitz, C., \& Gonnella, J. S. (2011). Physicians' empathy and clinical outcomes for diabetic patients. Academic Medicine : Journal of the Association of American Medical Colleges, 86(3), 359-364.

Hróbjartsson, A., \& Gøtzsche, P. C. (2001). Is the placebo powerless? An analysis of clinical trials comparing placebo with no treatment. The New England Journal of Medicine, 344(21), 1594-1602.

Hróbjartsson, A., \& Gøtzsche, P. C. (2004). Is the placebo powerless? Update of a systematic review with 52 new randomized trials comparing placebo with no treatment. Journal of Internal Medicine, 256(2), 91-100. 
Hróbjartsson, A., \& Norup, M. (2003). The use of placebo interventions in medical practice-a national questionnaire survey of Danish clinicians. Evaluation $\mathcal{E}$ the Health Professions, 26(2), 153-165.

Hull, S. C., Colloca, L., Avins, A., Gordon, N. P., Somkin, C. P., Kaptchuk, T. J., \& Miller, F. G. (2013). Patients' attitudes about the use of placebo treatments: Telephone survey. BMJ (Clinical Research Ed.), 347, f3757.

Hyland, M. E. (2011). Motivation and placebos: Do different mechanisms occur in different contexts? Philosophical Transactions of the Royal Society of London.Series B, Biological Sciences, 366(1572), 1828-1837.

Hyland, M. E., Geraghty, A. W., Joy, O. E., \& Turner, S. I. (2006). Spirituality predicts outcome independently of expectancy following flower essence self-treatment. Journal of Psychosomatic Research, 60(1), 53-58.

Hyland, M. E., \& Whalley, B. (2008). Motivational concordance: An important mechanism in self-help therapeutic rituals involving inert (placebo) substances. Journal of Psychosomatic Research, 65(5), 405-413.

Hyland, M. E., Whalley, B., \& Geraghty, A. W. (2007). Dispositional predictors of placebo responding: A motivational interpretation of flower essence and gratitude therapy. Journal of Psychosomatic Research, 62(3), 331-340.

Jensen, K. B., Petrovic, P., Kerr, C. E., Kirsch, I., Raicek, J., Cheetham, A., Spaeth, R., Cook, A., Gollub, R. L., Kong, J., Kaptchuk, T. J. (2014). Sharing pain and relief: Neural correlates of physicians during treatment of patients. Molecular Psychiatry, 19(3), 392-398.

Kam-Hansen, S., Jakubowski, M., Kelley, J. M., Kirsch, I., Hoaglin, D. C., Kaptchuk, T. J., \& Burstein, R. (2014). Altered placebo and drug labeling changes the outcome of episodic migraine attacks. Science Translational Medicine, 6(218), 218ra5.

Kaptchuk, T. J., Friedlander, E., Kelley, J. M., Sanchez, M. N., Kokkotou, E., Singer, J. P., Kowalczykowski, M., Miller, F. G., Kirsch, I., \& Lembo, A. J. (2010). Placebos without deception: A randomized controlled trial in irritable bowel syndrome. PloS One, 5, e15591.

Kaptchuk, T. J., Kelley, J. M., Conboy, L. A., Davis, R. B., Kerr, C. E., Jacobson, E. E., Kirsch, I., Schyner, R. N., Nam, B. H., Nguyen, L. T., Park, M., Rivers, A. L., McManus, C., Kokkotou, E., Drossman, D. A., Goldman, P., \& Lembo, A. J. (2008). Components of placebo effect: Randomised controlled trial in patients with irritable bowel syndrome. BMJ (Clinical Research Ed.), 336, 999-1003.

Keefe, F. J., Lumley, M., Anderson, T., Lynch, T., Studts, J. L., \& Carson, K. L. (2001). Pain and emotion: New research directions. Journal of Clinical Psychology, 57(4), 587-607.

Kelley, J. M., Kraft-Todd, G., Schapira, L., Kossowsky, J., \& Riess, H. (2014). The influence of the patient-clinician relationship on healthcare outcomes: A systematic review and meta-analysis of randomized controlled trials. PloS One, 9(4), e94207.

Kelley, J. M., Lembo, A. J., Ablon, J. S., Villanueva, J. J., Conboy, L. A., Levy, R., Marci, C. D., Kerr, C. E., Kirsch, I., Jacobsen, E. E., Riess, H. \& Kaptchuk, T. J. (2009). Patient and practitioner influences on the placebo effect in irritable bowel syndrome. Psychosomatic Medicine, 71(7), 789-797.

Kermen, R., Hickner, J., Brody, H., \& Hasham, I. (2010). Family physicians believe the placebo effect is therapeutic but often use real drugs as placebos. Family Medicine, 42(9), 636-642. 
Kessner, S., Sprenger, C., Wrobel, N., Wiech, K., \& Bingel, U. (2013a). Effect of oxytocin on placebo analgesia: A randomized study. JAMA: The Journal of the American Medical Association, 310(16), 1733-1735.

Kessner, S., Wiech, K., Forkmann, K., Ploner, M., \& Bingel, U. (2013b). The effect of treatment history on therapeutic outcome: An experimental approach. JAMA Internal Medicine, 173(15), 1468-1469.

Kirsch, I. (1999). How expectancies shape experience. Washington, DC: American Psychological Association.

Kirsch, I. (2013). The placebo effect revisited: Lessons learned to date. Complementary Therapies in Medicine, 21(2), 102-104.

Kirsch, I., \& Weixel, L. J. (1988). Double-blind versus deceptive administration of a placebo. Behavioral Neuroscience, 102(2), 319-323.

Klinger, R., \& Flor, H. (2013). The potential of the analgesic placebo effect in clinical practice - recommendations for pain management. In L. Colloca, M. A. Flaten \& K. Meissner (Eds.), Placebo and pain - from bench to bedside (pp. 267-275). Amsterdam; Boston: Academic Press.

Klinger, R., Soost, S., Flor, H., \& Worm, M. (2007). Classical conditioning and expectancy in placebo hypoalgesia: A randomized controlled study in patients with atopic dermatitis and persons with healthy skin. Pain, 128(1-2), 31-39.

Kong, J., Gollub, R. L., Rosman, I. S., Webb, J. M., Vangel, M. G., Kirsch, I., \& Kaptchuk, T. J. (2006). Brain activity associated with expectancy-enhanced placebo analgesia as measured by functional magnetic resonance imaging. The Journal of Neuroscience : The Official Journal of the Society for Neuroscience, 26(2), 381-388.

Kupers, R., Maeyaert, J., Boly, M., Faymonville, M. E., \& Laureys, S. (2007). Naloxone-insensitive epidural placebo analgesia in a chronic pain patient. Anesthesiology, 106(6), 1239-1242.

Laska, E., \& Sunshine, A. (1973). Anticipation of analgesia. A placebo effect. Headache, 13(1), $1-11$.

Levine, J. D., \& Gordon, N. C. (1984). Influence of the method of drug administration on analgesic response. Nature, 312(5996), 755-756.

Levine, J. D., Gordon, N. C., \& Fields, H. L. (1978). The mechanisms of placebo analgesia. Lancet, 2, 654-657.

Lichtenberg, P., Heresco-Levy, U., \& Nitzan, U. (2004). The ethics of the placebo in clinical practice. Journal of Medical Ethics, 30(6), 551-554.

Linde, K., Friedrichs, C., Alscher, A., Wagenpfeil, S., Meissner, K., \& Schneider, A. (2014). The use of placebo and non-specific therapies and their relation to basic professional attitudes and the use of complementary therapies among german physicians--a crosssectional survey. PloS One, 9(4), e92938.

Linde, K., Streng, A., Jurgens, S., Hoppe, A., Brinkhaus, B., Witt, C., Wagenpfeil, S., Pfaffenrath, V., Hammes, M. G., Weidenhammer, W., Willich, S. N., \& Melchart, D. (2005). Acupuncture for patients with migraine: A randomized controlled trial. Jama, 293(17), 2118-2125.

Linde, K., Witt, C. M., Streng, A., Weidenhammer, W., Wagenpfeil, S., Brinkhaus, B., Willich, S. M., \& Melchart, D. (2007). The impact of patient expectations on outcomes in four randomized controlled trials of acupuncture in patients with chronic pain. Pain, 128(3), 264-271. 
Lund, K., Vase, L., Petersen, G. L., Jensen, T. S., \& Finnerup, N. B. (2014). Randomised controlled trials may underestimate drug effects: Balanced placebo trial design. PloS One, 9(1), e84104.

Lyby PS, Aslaksen PM, Flaten MA. (2010). Is fear of pain related to placebo analgesia? Journal of Psychosomatic Research, 68(4), 369-377.

Lyby, P. S., Forsberg, J. T., Åsli, O., \& Flaten, M. A. (2012). Induced fear reduces the effectiveness of a placebo intervention on pain. Pain, 153(5), 1114-1121.

Melchart, D., Streng, A., Hoppe, A., Brinkhaus, B., Witt, C., Wagenpfeil, S., Pfaffenratt, V., Hammes, M., Hummelsberger, J., Irnich, D., Weidenhammer, W., Willich, S. N., \& Linde, K. (2005). Acupuncture in patients with tension-type headache: Randomised controlled trial. BMJ (Clinical Research Ed.), 331(7513), 376-382.

Miller, F. G., \& Colloca, L. (2009). The legitimacy of placebo treatments in clinical practice: Evidence and ethics. The American Journal of Bioethics : AJOB, 9(12), 39-47.

Moerman, D. E. (2013). Against 'placebo'. the case for changing our language, and for the meaning response. In L. Colloca, M. A. Flaten \& K. Meissner (Eds.), Placebo and pain from bench to bedside (pp. 183-188). Amsterdam; Boston: Academic Press.

Nitzan, U., \& Lichtenberg, P. (2004). Questionnaire survey on use of placebo. BMJ (Clinical Research Ed.), 329(7472), 944-946.

Pecina, M., \& Zubieta, J. (2013). Molecular mechanisms of placebo responses in humans. In L. Colloca, M. A. Flaten \& K. Meissner (Eds.), Placebo and pain - from bench to bedside (pp. 25-35). Amsterdam; Boston: Academic Press.

Petersen, G. L., Finnerup, N. B., Grosen, K., Pilegaard, H. K., Tracey, I., Benedetti, F., Price, D. D., Jensen, T. S., \& Vase, L. (2014). Expectations and positive emotional feelings accompany reductions in ongoing and evoked neuropathic pain following placebo interventions. Pain, 155 (12), 2687-2698.

Petersen, G. L., Finnerup, N. B., Nørskov, K. N., Grosen, K., Pilegaard, H. K., Benedetti, F., Price, D. D., Jensen, T. S., \& Vase, L. (2012). Placebo manipulations reduce hyperalgesia in neuropathic pain. Pain, 153(6), 1292-1300.

Petrovic, P., Kalso, E., Petersson, K. M., \& Ingvar, M. (2002). Placebo and opioid analgesia-imaging a shared neuronal network. Science (New York, N.Y.), 295(5560), 1737-1740.

Price, D. D. (2005). New facts and improved ethical guidelines for placebo analgesia. The Journal of Pain: Official Journal of the American Pain Society, 6(4), 213-214.

Price, D. D., Craggs, J., Verne, G. N., Perlstein, W. M., \& Robinson, M. E. (2007). Placebo analgesia is accompanied by large reductions in pain-related brain activity in irritable bowel syndrome patients. Pain, 127(1-2), 63-72.

Price, D. D., Finniss, D. G., \& Benedetti, F. (2008). A comprehensive review of the placebo effect: Recent advances and current thought. Annual Review of Psychology, 59, 565-590.

Price, D. D., Milling, L. S., Kirsch, I., Duff, A., Montgomery, G. H., \& Nicholls, S. S. (1999). An analysis of factors that contribute to the magnitude of placebo analgesia in an experimental paradigm. Pain, 83(2), 147-156.

Rhudy, J. L., Williams, A. E., McCabe, K. M., Russell, J. L., \& Maynard, L. J. (2008). Emotional control of nociceptive reactions (ECON): Do affective valence and arousal play a role? Pain, 136(3), 250-261.

Rief, W., Avorn, J., \& Barsky, A. J. (2006). Medication-attributed adverse effects in placebo groups: Implications for assessment of adverse effects. Archives of Internal Medicine, 166(2), 155-160. 
Ross, S., Krugman, A. D., Lyerly, S. B., \& Clyde, D. J. (1962). Drugs and placebos: A model design. Psychological Reports, 10(2), 383.

Schenk, L. A., Sprenger, C., Geuter, S., \& Büchel, C. (2014). Expectation requires treatment to boost pain relief: An fMRI study. Pain, 155(1), 150-157.

Scott, D. J., Stohler, C. S., Egnatuk, C. M., Wang, H., Koeppe, R. A., \& Zubieta, J. K. (2007). Individual differences in reward responding explain placebo-induced expectations and effects. Neuron, 55(2), 325-336

Scott, D. J., Stohler, C. S., Egnatuk, C. M., Wang, H., Koeppe, R. A., \& Zubieta, J. K. (2008). Placebo and nocebo effects are defined by opposite opioid and dopaminergic responses. Archives of General Psychiatry, 65(2), 220-231.

Tilburt, J. C., Emanuel, E. J., Kaptchuk, T. J., Curlin, F. A., \& Miller, F. G. (2008). Prescribing »placebo treatments «: Results of national survey of US internists and rheumatologists. BMJ (Clinical Research Ed.), 337, a1938.

Vase, L., Nørskov, K. N., Petersen, G. L., \& Price, D. D. (2011). Patients' direct experiences as central elements of placebo analgesia. Philosophical Transactions of the Royal Society of London.Series B, Biological Sciences, 366(1572), 1913-1921.

Vase, L., \& Petersen, G. L. (2013). Conceptualizations and magnitudes of placebo analgesia effects across meta-analyses and experimental studies. In L. Colloca, \& Flaten, M. A., Meissner, K. (Eds.), Placebo and pain - from bench to bedside (pp. 203-214). Amsterdam; Boston: Academic Press.

Vase, L., Petersen, G. L., Riley, J. L.,3rd, \& Price, D. D. (2009). Factors contributing to large analgesic effects in placebo mechanism studies conducted between 2002 and 2007. Pain, 145(1-2), 36-44.

Vase, L., Riley, J. L.,3rd, \& Price, D. D. (2002). A comparison of placebo effects in clinical analgesic trials versus studies of placebo analgesia. Pain, 99(3), 443-452.

Vase, L., Robinson, M. E., Verne, G. N., \& Price, D. D. (2003). The contributions of suggestion, desire, and expectation to placebo effects in irritable bowel syndrome patients. an empirical investigation. Pain, 105(1-2), 17-25.

Vase, L., Robinson, M. E., Verne, G. N., \& Price, D. D. (2005). Increased placebo analgesia over time in irritable bowel syndrome (IBS) patients is associated with desire and expectation but not endogenous opioid mechanisms. Pain, 115(3), 338-347.

Vase, L., Skyt, I., Petersen, G. L., \& Price, D. D. (2014). Placebo and nocebo effects in chronic pain patients: How expectations and emotional feelings contribute to the experience of pain. Zeitschrift Für Psychologie, 222(3), 135-139.

Verne, G. N., Robinson, M. E., Vase, L., \& Price, D. D. (2003). Reversal of visceral and cutaneous hyperalgesia by local rectal anesthesia in irritable bowel syndrome (IBS) patients. Pain, 105(1-2), 223-230.

Voudouris, N. J., Peck, C. L., \& Coleman, G. (1989). Conditioned response models of placebo phenomena: Further support. Pain, 38(1), 109-116.

Voudouris, N. J., Peck, C. L., \& Coleman, G. (1990). The role of conditioning and verbal expectancy in the placebo response. Pain, 43(1), 121-128.

Wager, T. D., Rilling, J. K., Smith, E. E., Sokolik, A., Casey, K. L., Davidson, R. J., Kosslyn, S. M., Rose, R. M., \& Cohen, J. D. (2004). Placebo-induced changes in FMRI in the anticipation and experience of pain. Science (New York, N.Y.), 303, 1162-1167. 
Witt, C., Brinkhaus, B., Jena, S., Linde, K., Streng, A., Wagenpfeil, S., Hummelsberger, J., Walther, H. U., Melchart, D., \& Willich, S. N. (2005). Acupuncture in patients with osteoarthritis of the knee: A randomised trial. Lancet, 366(9480), 136-143.

Zubieta, J. K., Bueller, J. A., Jackson, L. R., Scott, D. J., Xu, Y., Koeppe, R. A., Nichols, T. E., \& Stohler, C. S. (2005). Placebo effects mediated by endogenous opioid activity on muopioid receptors. The Journal of Neuroscience: The Official Journal of the Society for Neuroscience, 25, 7754-7762. 